\title{
CECílIA TÃo LEVE, CECÍLIA TÃo BELA
}

\section{Lenice Pimentel ${ }^{(*)}$}

Cecília que é a reinvenção da vida

na poesia,

borboleta pousando na flor da língua.

Maurício de Macedo

Resumo:Do livro A ostra e a pérola, de Maurício de Macedo, emerge o conto "Cecília Meireles" apontando claramente para a intertextualidade que permeia a literatura. O tom intimista e lírico conduz esse fazer poético, que tem na palavra o segredo da aventura humana no seu (re)inventar-se através do ato da escritura, uma vez que o escrito produz o sujeito enquanto enfrenta o desafio da folha em branco.

Palavras-chave: Literatura; escritura; psicanálise

Saindo do casulo, rompendo as barreiras do "arquipélago cultural", Maurício de Macedo tem nos presenteado com sua escrita madura e enraizada no massapé das Alagoas de onde puxa a memória do ontem para juntar com a vivência do hoje. É com essa argamassa que tece e torce a palavra até onde ela grita mais fundo: a escritura. Nesse duelo com a palavra, o poeta junta passado, presente e futuro e arrisca abordar a condição humana na sua face de vida e morte. Sua poesia pensa e faz pensar quem por seus caminhos resolve caminhar, de preferência cavalgando Pégaso. De tom intimista, a lírica poética de Maurício de Macedo reverbera em todo o livro A ostra e a pérola e expressa sua visão de mundo com as cores fortes da subjetivação, talhada com o cinzel da língua e com o árduo trabalho da leitura. É nessa tradição que ele dialoga com Cecília Meireles sem truques. Homenageia a poetisa escolhendo-a para epígrafe do livro e dando seu nome a um dos poemas, sobre o qual vou me deter. Retomo a epígrafe ceciliana para ressaltar a força do lírico que invade a escrita do poeta alagoano.

(*) Doutora em Literatura pela Universidade Federal de Alagoas c psicanalista ligada ao Centro de Estudos Freudianos do Recife.

1 MACEDO, M. de. A ostra e a pérola. Olinda/Pernambuco: Livro Rápido. 2003. 
Vou pelo braço da noite,

Levando tudo que é meu:

- a dor que os homens me deram,

e a canção que Deus me deu.

Cecília, Cecília... Cecília tão leve, Cecília tão bela... Que Cecília? A Cecília que permanece no poeta. A Cecília que o toma pelo "braço da noite" para ensinar-lhe a ouvir as dores humanas e os sons divinos. A Cecília que está "suspensa na eternidade, no tempo do mito,/ onde as palavras se despojam/ dos engodos da glória e do poder.// Cecília tão leve,/ Cecília tão bela." conduz a rima para expressar a relação do eu com o mundo.

Na cadência dos versos, o poeta voa nas palavras e revela os segredos da aventura humana no seu (re)inventar-se através do ato da escritura, uma vez que o escrito produz o sujeito, mesmo que implique uma "certa condição de exílio daquele que enfrenta o desafio do escrever", reconhecendo a intertextualidade que perpassa pelo fazer poético (BARTUCCI, 2001, p.14).

No desafio de escrever um texto a partir de outro texto produzir uma escritura -, vou construindo um "lugar-outro" para reafirmar o caráter auto-suficiente do texto literário com as marcas dessa nova leitura. Mexer no texto, desarrumá-lo, re-escrevê-lo, aproveitar os efeitos que o mesmo me provoca é, sem dúvida, uma via para recuperar o próprio sentido da produção literária, fato este que Freud já apontava como semelhante ao processo primário. Frente ao poema "Cecília Meireles", o que me fascina são os efeitos do inconsciente, ou seja, ao ler o texto para realizar a crítica psicanalítica, o que realizo é o "desligamento", para usar a terminologia de André Green (1994), das marcas que perduram no sujeito na dimensão do olhar e da escuta. A interpretação psicanalítica da obra literária tem se modificado para acompanhar os inúmeros deslocamentos do desejo nas tessituras do texto, ou seja, tem seguido o método interpretativo aplicado ao texto literário. Para Carvalho,

uma abordagem psicanalítica do literário se dará se levarmos em conta o núcleo de verdade (do desejo) escondido e revelado [...]na concretude das linhas que tecem o texto. [...] Ao levarmos a interpretação psicanalítica para o campo da crítica literária, não tiramos dela sua função primordial. Ao contrário, se é 
próprio da interpretação psicanalítica 'delirar', isto é, 'tirar o texto de sua trilha' (...).sua eficácia está justamente em mostrar que, no desvendamento das relações do texto com o inconsciente, faz surgir uma outra realidade que não é a literária. A interpretação psicanalítica do literário revela, na materialidade mais concreta da escrita, o trabalho de transformação (...) de algo que não é literário, em realidade literária, isto é ficcional.

Assim, finalmente, a abordagem psicanalítica do literário permitirá ver como a realidade psíquica, noção tão cara à psicanálise pelos seus efeitos de verdade sobre o sujeito, reencontra no poético e no ficcional o veículo que lhe dá corpo fora da alternativa sempre possível do sintoma e das outras manifestações psíquicas, concentrando-se no ponto enigmático e limite onde essas, verdadeiras pegadas clínicas, invertem-se em 'efeitos de criação'. (...) Apagando-se no literário os limites entre o que é realidade e o que é ficção, é a interpretação que irá evidenciar, pelo poético da linguagem, a eficácia da ficção como verdade. ${ }^{2}$

Tomada como ficção, a realidade psíquica terá assim efeito de verdade na medida em que o desejo é refeito na escritura acompanhando o que Freud já dizia sobre a interpretação: sair do texto manifesto disposto a encontrar no texto latente o sentido que ali sonha. A esse respeito Laplanche ressalta a necessidade de "esclarecer um texto, mas segundo o seu verdadeiro sentido, dizer a verdade, encontrar a significação imanente: a Bedeutung". ${ }^{3}$ Nada podemos acrescentar ao texto que já não esteja lá e no entanto o desejo de encontrar essa "significação imanente" não se sustenta quando adotamos a perspectiva de que o sentido do texto se dá no encontro com o leitor. O significado está atrelado ao texto mas precisa ser de lá arrancado pelo leitor que o coloca em movimento. O olhar do leitor

2 CARVAlHO, Ana Cecília. É possível uma crítica literária psicanalítica? Percurso, Revista de psicanálise. São Paulo, ano XI, n.22, p. 67; $1^{\circ}$ semestre de 1999, grifo nosso.

3 LAPLANCHE, Jean. (s/d) Interpretar [con] Freud. In: Laplanche, J. y otros. Interpretación freudiana y psicoanálisis. Buenos Aires, Piados, 1987, p. 58. 
detecta as lacunas possíveis do texto e na interação com o mesmo, produz significado e sentido.

Como leitora, portando meu próprio texto, já tão atravessado de vozes pretéritas, não pude me esquivar de "escutar" a sonoridade árcade na poesia de Maurício de Macedo e, devagar, fui dele me apropriando para reescrever nas suas lacunas um outro texto literário. Ancorada no significante Cecília, arrisco-me a puxar os efeitos dessa leitura que se produzem no espaço entre a ficção literária e meus próprios fantasmas uma vez que "não se pode escrever sem a força do corpo." Articular a psicanálise com o campo da literatura tem sido um exercício constante para os psicanalistas que desejam alargar o caminho apontado por Freud e Lacan. Ambas, psicanálise e literatura, lidam com a linguagem, produzindo efeitos que se negam a permanecer prisioneiros de um único saber. Assim, não se pode escrever sem praticar uma certa antropofagia, e é isso que vejo no poema "Cecília Meireles" quando o autor, em seus processos identificatórios, busca no baú de suas leituras o alimento para o desejo de construir uma singularidade que o inscreva no seu próprio estilo. A repetição dos versos 'Cecília tão leve, Cecília tão bela' evidencia a força do significante na palavra que se deseja visível ou figurada.
Leia-se no poema:

Cecília tão leve

Cecília tão bela.

Sombra e sol, Solombra

Cecília profeta

e a luz pousando sobre seu silêncio,

sobre sua sombra, iluminando os segredos,

fazendo falar as palavras do sono.

Os versos vão se criando e adquirindo novas significações, evitando o fechamento do texto. O texto pulsa. Cecília, recriada, se projeta na sua magnitude de dama da literatura brasileira e ilumina as palavras do poeta como se fosse "o sol da primavera", acordando pequenos seres alados que dormitam na gramática. As sombras, o sono, a canção ou o silêncio facilitam as travessuras linguageiras desse poeta alagoano que se alia à "Cecília Ariadne desenrolando o novelo / nos labirintos do esquecimento, / nas galerias das minas dos

\footnotetext{
DURAS, Marguerite. Escrever. Rio de Janeiro: 1994, p. 23.
} 
silêncios gerais", em busca de seus segredos, de seus mistérios, de seus versos.

O fio de Ariadne conduz o poeta através das galerias das palavras, desenterrando a imaginação lírica em busca do entulho que movimenta a rima, a repetição, a sonoridade, o desejo. A cada passo, os ecos, espelhos e ressonâncias da poetisa, se fazem presentes para dizer desse Real. Leveza e beleza se juntam na poesia de Maurício de Macedo que, "recolhendo das águas do espelho/ nas mãos em concha,/ os naufrágios do tempo e as pétalas da lembrança", continua acionando "as forças motrizes deste nosso tempo de perplexidades e metamorfoses, em que o aqui-e-agora se sabe resultante da semeadura do ontem e, também, gênese obscura do amanha $\tilde{a}^{5}$ que se alumbra "com a tocha da poesia".

O olhar-texto que recupera Cecília Meireles é o lugar mesmo onde a psicanálise exige que a literatura pense e se repense enquanto letra, pois é, ao mesmo tempo, representação e apresentação do sujeito-poeta que aí comparece enquanto significante. Na repetição do nome Cecília, o que encontramos é a resistência da literatura, da tradição mais pura da lírica e, nos versos, o amanhã se tece "entre o fugaz e o eterno,/ o bater das asas do vôo/ da rolinha da palavra." Cecília tão leve,/ Cecília tão bela, metáfora do sujeito-poeta, ele recupera e reafirma na palavra sua condição de se fazer ouvir. Repetindo o diferente, a poesia de Maurício de Macedo se constrói ancorada no nome de Cecília Meireles, pois "torna-se letra do corpo do poeta, com seu estilo, seu stylo, metonímia do corpo, onde tudo pulsa e por onde tudo passa" em poesia que "atua como um roteiro, como uma maneira de ver" trabalhar tão bem essa intertextualidade.

O poeta Maurício continua imerso no "barro ensangüentado da palavra,/ pó da vida e da morte", nele buscando a "Cecília Ariadne" para dar forma a novos tecidos-textos que se desprendem do papel e se

5 Novaes Coelho, Nelly. "Onde a vida fere mais fundo...". O nome do Jornal? Fev./2000- Seção 'Linguagem Viva'.Tem a data'?

6 BRANDÃO, Ruth Silviano. Literatura e psicanálise. Porto Alcore: UFRGS, 1996, p.31.

7 BERNARDES, Denis Antônio de Mendonça, professor do Departamento de História da UFPE, ao prefaciar o livro inédito - Das Alagoas e Guerreiro. 
fazem signos na "Música do vento e do mar,/ canção na asa da palavra no ar,/ silêncio das galerias das minas do esquecimento./ [Propagando a] Cecília aedo,/ Cecília sabiá." Cecília é signo trespassado pela presença/ausência da morte, "lugar onde ele mesmo, o poeta, pode-se abismar, já que essas bordas são finas bordas, finos limites”, como assinala Ruth S.Brandão (1996, p.32).

A presença/ausência dos sons cecilianos na poesia de Maurício de Macedo continua "fazendo da poesia o lugar não do fácil engano, mas do enfrentamento corajoso, de quem sabe o que faz"s e re-edita a condição da criação, da vida, da poesia que ecoa nos versos: Cecília tão leve,/ Cecília tão bela. "Afinal, o que é o poético senão essa busca da coisa que antecede à palavra e esse paradoxo incessante de se buscar a coisa justamente através de palavras"9 naquilo que elas fazem semblante? Incrustada na placenta da linguagem, a poesia macediana é pura arte, e no poema "Cecília Meireles" as vozes do palco literário se repetem, se invertem e se subvertem para alçar seu vôo maior: encenar o possível do desejo no momento mesmo em que perpetuando o "tempo arquetípico".

\section{Referências bibliográficas}

BARTUCCI,Giovanna. Psicanálise, literatura e estéticas de subjetivação. Tradução Sylvio Horta.Rio de Janeiro: Imago, 1996. BRANCO, L. Castello. O que é escrita feminina. São Paulo:
Brasiliense: 1991. BRANDÃO, Ruth Silviano. Literatura e psicanálise. Porto Alegre:
Ed. Universidade/ UFRGS. 1996.

BERNARDES, Denis Antônio de Mendonça, professor do Departamento de História da UFPE, ao prefaciar o livro inédito - Das Alagoas seguido de guerreiro (lançado em outubro/2003).

8 LIMA, Roberto Sarmento. Existe uma poesia alagoana? Gazeta de Alagoas, Maceió, [s/d.].

9 BRANCO, L. Castello. O que é escrita feminina. São Paulo: Brasiliense: 1991, p.75. 
CARVAlHO, Ana Cecília. É possível uma crítica literária psicanalítica? Percurso, Revista de psicanálise. São Paulo, ano XI, n.22, $1^{\circ}$ semestre de 1999.

DURAS, Marguerite. Escrever. Rio de Janeiro: 1994.

GREEN, André. $O$ desligamento. Psicanálise, antropologia e literatura. Rio de Janeiro: Imago, 1994.

LAPLANCHE, Jean. (s/d) Interpretar [con] Freud. In: LAPLANCHE,

J. y otros. Interpretación freudiana y psicoanálisis. Buenos Aires: Piados, 1987.

LIMA, Roberto Sarmento. Existe uma poesia alagoana? Gazeta de Alagoas, Maceió, (s/d).

MACEDO, M. de. A ostra e a pérola. Olinda/Pernambuco: Livro Rápido, 2003.

NOVAES COELHO, Nelly. "Onde a vida fere mais fundo...". Fev./2000- Seção 'Linguagem Viva'. 